\title{
Level of Maternal Stress during two pregnancy periods on rat offspring behaviors'
}

MIKE MORRA

XAVIER UNIVERSITY

\begin{abstract}
Abstraet
Four levels of prenatal stress and two periods during pregnancy were used in this study in an attempt to systematically investigate the varying influences of the prenatal environment on postnatal offspring behaviors. The data suggested significant behavioral decrement in offspring whose mothers were exposed to stress during the second half of pregnancy. In addition, greater behavioral deficit was significantly associated with greater levels of stress. Rates of fertility and viability of the stressed animals were also significantly reduced. Problem
\end{abstract}

Thompson (1957) found that maternal fear during pregnancy resulted in a significant decrease of activity in the offspring. Doyle \& Yule (1959), Hockman (1961), Ader \& Belfer (1962), Thompson (1962), and Fries \& Weir (1964) have replicated this original report with varying parameter changes.

In Thompson's (1957) study, an attempt was made to test the hypothesis that emotional trauma, as experienced by female rats during pregnancy, would affect the emotional characteristics of the offspring. Thompson felt that strong emotions may release substances into the fetal blood stream via the placental barrier and influence the development of the fetus. To demonstrate this phenomenon, Thompson pretrained female rats to avoid electric shock at the sound of a buzzer. He then mated the animals and exposed them to the stimulus conditions of the pretraining phase devoid of the shock. This treatment tended to induce fear in the mothers irrespective of actual pain. The offspring were then tested in the open field and compared to control rats.

The other investigators, who have used Thompson's experimental format, considered the following parameter changes: (1) different UCS intensities; (2) different criteria for the pre-pregnancy avoidance habit; (3) different offspring testing days; (4) different fostering procedures; (5) different interstimulus intervals; (6) different number of trials during pregnancy; (7) activity matching of mothers and males; (8) handling of control mothers during pregnancy; (9) response prevention or elicitation during pregnancy trials.

The purpose of this study was to extend further Thompson's (1957) design by controlling additional variables and by attempting to increase the generality of these previous findings by the use of a different UCS i.e., intense heat. A $2 \times 4$ design was used which was characterized by four levels of stress (defined in terms of number of avoidance exposures prior to conception) and two critical periods during pregnancy (1st and 2nd halves). Intense radiant heat instead of electric shock was the UCS used during the pre-pregnancy avoidance training.

\section{Method}

The Ss were 40,120 -day old, female albino rats of the Wistar strain. They were divided randomly into eight groups represented by four levels of stress (i.e. $0,50,100$, and 200 CS-UCS pairings prior to conception) and two CS-only exposure periods during pregnancy (i.e. early pregnancy, Days 1-9; late pregnancy, Days 11-19).

The pre-pregnancy avoidance training was administered to the female rats at the rate of 10 consecutive trials a day for 17 successive days. A modified Mowrer-Miller avoidance shuttlebox was used whose internal dimensions were: length, $2 \mathrm{ft}$; width, 9 in; height, 9 in. Radiant heat was supplied by three overhanging heat lamps $(250 \mathrm{w})$ which were fastened to a hinged attachment on top of the shuttlebox. The CS-UCS interval was set at $3 \mathrm{sec}$. and the intertrial interval was $57 \mathrm{sec}$. The UCS was maintained throughout the intertrial interval. Before the first trial of each day, the lamps were preheated for a 2-min. period. Pretraining began with the 200-trial group. Ten days later, training began for the 100-trial group and finally, five days later the 50-trial group began its training. The pretraining for all six groups terminated on the same day.

After this avoidance conditioning, the females were mated for three consecutive days in groups of five males and five females per cage. The vaginal smear technique was not used in that it added an undesired stress factor. All the litters were born within six days (Days 22-28) which suggested that the probable maximum overlap between the early pregnancy groups and the late pregnancy groups was three days. This variation of litter births allowed us to redefine our periods of pregnancy as follows: early pregnancy, Days 1-4 to 11 ; late pregnancy, Days $9-11$ to 19 . The number of offspring produced per group is presented in Table 1.

On Day 19 of pregnancy (counting from Day 1 of mating), the animals were isolated and were given equal amounts of nesting materials. No cross-fostering was used, however the 0-trial groups received equal handling during pregnancy. The offspring were weaned on Day 23 and were tested two days later in the open field whose dimensions were: length, 25 in; width, $25 \mathrm{in}$; height, $2 \mathrm{ft}$. Each rat received one 1-min. trial in the open field.

Each rat was also tested in a simple water $\mathrm{T}$ maze whose dimensions were: length, $1-1 / 2 \mathrm{ft}$; width, $9 \mathrm{in}$; 
TABLE I. OPEN FIELD AND I MAZE PERFORMANCES OF OFFSPRING

\begin{tabular}{|c|c|c|c|c|c|c|c|c|}
\hline \multicolumn{9}{|c|}{ Level of Stress } \\
\hline & \multicolumn{2}{|c|}{ D-Trials } & \multicolumn{2}{|c|}{$50-$ Trials } & \multicolumn{2}{|c|}{$100-$ Trials } & \multicolumn{2}{|c|}{ 200-Trials } \\
\hline & $\begin{array}{r}\text { lst } \\
\text { Half } \\
\end{array}$ & $\begin{array}{r}2 \text { nd } \\
\text { Half }\end{array}$ & $\begin{array}{r}\text { Ist } \\
\text { Half } \\
\end{array}$ & $\begin{array}{c}\text { 2nd } \\
\text { Half } \\
\end{array}$ & $\begin{array}{r}1 \text { st } \\
\text { Half }\end{array}$ & $\begin{array}{c}2 \text { nd } \\
\text { Half }\end{array}$ & $\begin{array}{r}\text { lst } \\
\text { Half }\end{array}$ & $\begin{array}{r}2 \text { nd } \\
\text { Half }\end{array}$ \\
\hline Number Offspring & 21 & 8 & 17 & 20 & 21 & 17 & 12 & 12 \\
\hline $\begin{array}{l}\text { Mean Open-field } \\
\text { Traversals }\end{array}$ & 34 & 50 & 46 & 46 & 43 & 34 & 40 & 20 \\
\hline $\begin{array}{l}\text { Median Swimming } \\
\text { Times in T Maze }\end{array}$ & 14 & 24 & 13 & 11 & 15 & 11 & 11 & 11 \\
\hline $\begin{array}{l}\text { Median \% Correct } \\
\text { in T Maze }\end{array}$ & 58 & 38 & 67 & 75 & 58 & 71 & 75 & 75 \\
\hline
\end{tabular}

height, $18 \mathrm{in}$, for both the stem and both arms of the maze. The water level was set at 12 in and was changed daily. Its temperature varied between $68-73^{\circ} \mathrm{F}$. Two $60 \mathrm{w}$ shielded bulbs provided uniform lighting in a completely darkened room. Each light was placed 5 in over the end of an arm.

Each animal received five consecutive trials on one day in the $\mathrm{T}$ maze. The intertrial interval was $30 \mathrm{sec}$. The goal-arm was constant for each arm and was alternated for each successive rat. The $\mathrm{T}$ maze testing was completed in four days (Days 35-38, postpartum) and all eight groups were represented on each of the four days of testing.

\section{Results and Discussion}

The results are presented in Table 1. Analyses of variance tests were applied to the open field and $T$ maze data and chi square tests were applied to the fertility and viability data. The analysis of the frequency of traversals measure in the open field yielded no significant differences between periods of pregnancy $(\mathrm{F}=1.38 ; \mathrm{df}=1,120)$. However significant differences $(p<.01)$ were obtained with the Level of Stress variable $(\mathrm{F}=5.59 ; \mathrm{df}=3,120)$ and with the Interaction of Stress $x$ Period $(F=6.77 ; d f=3,120)$. The higher mean number of traversals was associated with the non-stressed and lower stressed groups.

The $\mathrm{T}$ maze data was combined across the five trials since the testing for each rat was completed on one day. Statistical analysis of the swimming time measure in the $\mathrm{T}$ maze yielded significant differences for both the Stress variable and the Interaction of Stress x Period. No differences were obtained for the Period variable. The $F$ values for the three factors were as follows: Level of Stress $(\mathrm{F}=3.45 ; \mathrm{df}=3,120$; $\mathrm{p}<.05)$; Period of Pregnancy $(\mathrm{F}=1.16 ; \mathrm{df}=1,120$; $\mathrm{p}>.05)$; Interaction $(\mathrm{F}=2.70 ; \mathrm{df}=3,120 ; \mathrm{p}<.05)$. Faster speeds were associated with the higher stressed groups.

The only main effect obtained with the correctness measure was the Level of Stress variable $(F=5.24$; $\mathrm{df}=3,120 ; \mathrm{p}<.01)$. The more accurate performances were associated with the higher stressed groups. An analysis of the Period variable $(F=.01 ; d f=1,120)$ and the interaction $(F=1.71 ; d f=3,120)$ yielded no significant differences.
Chi-squared values of 38.06 and 11.21 were obtained for the number of offspring surviving to Day 25 measure and for the number of offspring born, respectively. These values were significant at the $p<.01$ level. Less fertility and less viability were associated with the higher stressed groups.

The conclusions that could be drawn from these data are: (a) Greater levels of conditioned stress during pregnancy seemed to result in greater emotionality in the offspring (i.e.less activity, faster swimming time, and greater accuracy). Greater accuracy and faster swimming time are often associated with greater emotionality (Broadhurst, 1957) in that emotional arousal is facilitative in a simple learning task (Hebb, 1955); (b) The latter phase of pregnancy seemed to be more sensitive to these treatments, however the actual days or embryological stages were not isolated in this study. There existed a 3-6 day overlap between the two periods of pregnancy which suggested that the third trimester was probably most critical. In the albino rat, the initiation of motor and sensory apparatus occurs from Day 14 to term; (c) Rates of fertility and viability seemed to have been adversely affected by these treatments. Hockman (1961) reported differences in the same direction at $\mathrm{p}<.005$. Doyle \& Yule (1959) and Ader \& Belfer (1962) also reported fewer stressed offspring.

\section{References}

Ader, R., \& Belfer, M. L. Prenatal maternal anxiety and offspring emotionality in the rat. Psychol. Rep., 1962, 10, 711-718.

Broadhurst, P. L. Emotionality and the Yerkes-Dodson Law. J. exp. Psychol., 1957, 54, 345-352.

Doyle, G., \& Yule, E. P. Early experience and emotionality: The effects of prenatal and maternal anxiety on the emotionality of albino rats. S. Afr. J. soc. Res., 1959, 10, 57-77.

Fries, J. L., \& Weir, M. W. Open-field behavior of C57BL/6J mice as a function of age, experience, and prenatal maternal stress. Psychon. Sci., 1964, 1, 389-390.

Hebb, D. Drive and the CNS. Psychol. Rev., 1955, 62, 243-250.

Hockman, C. H. Prenatal maternal stress in the rat. J. comp. physiol. Psychol., 1961, 54, 679-684.

Thompson, W. R. Influence of prenatal and maternal anxiety on emotionality in young rats. Science, 1957, 125, 698-699.

Thompson, W. R., Watson, J., \& Charlesworth, W. R. The effects of prenatal maternal stress on offspring behavior in rats. Psychol. Monogr., 1962, 76, 1-26, No. 38.

Note

1. Supported by the Veterans Administration, Augusta, Georgia. 